\title{
MASSACHUSETTS INSTITUTE OF TECHNOLOGY
}

$\mathrm{E}^{\mathrm{x}}$ XHILARATING is the only way to describe the report of the President of the Massachusetts Institute of Technology for 1963 . To read that, in 1960, M.I.T. launched a second century programme appeal with a minimum goal of 66 million dollars is challenging enough: to learn that in three years the appeal was closed with a total of 98 million dollars shows what a place M.I.T. holds in the life of the American peoples. The whole sum came from private philanthropy - alumni, friends of M.I.T., foundations, business and industry.

The report describes recent trends in the life of the Institute and the uses to which the collected moneys are to be put.

For the past eight years undergraduate enrolment has remained essentially level at about 3,600 , reflecting the decision prior to 1955 to limit first-year admissions to a class of 900. This is still M.I.T. policy and is a decision based on a balance of quality and resources. M.I.T. can educate only a fraction of the American undergraduate students in science and engineering and it can, at the most, contribute a limited number of young men and women of exceptional ability brought to the highest level of profes. sional competence. To stretch resources to accommodate another one hundred or two hundred students would be to risk the quality of the whole effort. It is in the capability and versatility of its graduates that M.I.T. makes a contribution to the Nation. Its central purpose is to provide them with a programme that will set standards and serve as a model of excellence in its fields of education.

The situation in the Graduate School is quite different. There has been an increase in graduate student enrolment of about 69 per cent. It relates to regular graduate students only, of whom there were some 2,600 last year, and does not include special part-time students who are not candidates for degrees. It is in the area of graduate study that the greatest demands - and the greatest shortages-will develop in the years directly ahead. There is a clear case for a policy which balances increases of enrolment against the rate of increase in the financial resources and the physical facilities of the institution.

To the undergraduate and graduate students should be added another category - the post-doctoral group. The rapid rise in the numbers in this category has been one of the notable phenomena of recent years at all major institutions. Until lately there was at M.I.T. only a handful: to-day, under various guises and classifications, there are several hundred.

In their interests and backgrounds they reveal the utmost diversity. Some are experienced and senior people with the support of fellowships; others, also with fellowships, have just received their doctorates; still others are simply visitors and guests, and come, for vary. ing periods, to work with particular professors. There is no uniformity in the procedures and arrangements for their affiliation and no formal policy governing their admission. That they contribute greatly is manifest, for they are active at the forefront of many fields and are welcome and stimulating associates of the faculty. Yot their presence does represent a new and uncomputed cost, and only a few post-doctoral fellowships provide even a small grant to the host institution.

In the changing pattern of American university life, these post-doctoral members are a new constituent. They bring a greater maturity than the regular students and are motivated in part by different aims and a different outlook. It seems inevitable that they will begin to take the form of a cohesive division, comparable to the emerg ence of the graduate school at an earlier period.

In the faculties, a most significant feature is the shift from engineering to science, a national phenomenon that has been the subject of much discussion. Undergraduate enrolment in science at M.I.T. has more than doubled, whereas the number of undergraduate majors in engineering, after reaching a peak in 1955, has fallen off sharply. Graduate engineering enrolment, on the other hand, is steadily rising, and the Institute is by a wide margin the nation's leading source of masters and doctors in engineering. There are signs that presage a strong renewa] of student interest in engineering.

There has also been a marked shift from undergraduate to graduate emphasis in the School of Management. The increase in undergraduate majors in the School of Humanities and Social Science reflects the interest in Course XXIhumanities and engineering or humanities and sciencewhile the rise of graduate enrolment in this same School is evidence of the important new role of economics, political science, psychology, and languages at M.I.T.

Expenditures for research at M.I.T. not only are continuing to rise but also in fact are increasing more rapidly than educational expenses. These expenditures are now slightly more than half the total academic expense. Although the ratio of 50 per cent for research to the total does not seem alarming for an institution of the character of M.I.T., the trend is giving concern. The Visiting Committee for Sponsored Research has directed particular attention to these mounting figures, and has urged a higher order of selectivity in accepting new programmes and continuing vigilance "to ensure that the further growth of campus research makes not only its well-recognized contributions to graduate education but also strengthens undergraduete instruction, providing the undergraduate with opportunities for participation which enrich his total educational experience".

The report contains a series of photographs indicating a few of the present activities at M.I.T. One of the most interesting is a diagram from a student thesis in management showing the interrelationships among groups in a large research and development organization.

\section{BONDING METALS WITH EXPLOSIVES}

ORMALLY, methods for cladding metals require
elaborate preparation, the use of intermediate
chemicals and materials, electrolytic processes, heat, or
other conventional procedures; at the least they are
time-consuming and frequently costly factors to be
reckoned with in the manufacture of metal protective
coatings. A recent demonstration in the Explosives
Department of E. I. du Pont de Nemours and Co.,
Wilmington, Delaware (Dupont Magazine, 58, No. 1;
January /February 1964), suggests a new and somewhat remarkable technique with far-reaching consequences if universally developed.

It is claimed that: "After covering a two-inch-thick sheet of carbon steel with a quarter-inch-thick sheet of stainless steel, a metals worker triggered a high explosives charge. The resulting explosion drove the stainless and carbon steels together into a uniform, permanently clad plate that can be easily fabricated. The metals' individual properties were unchanged by the impact; their bond .. . was as strong as one formed by conventional welding". 
It is pointed out that the force of the detonating explosive momentarily creates a thin zone of melted metal between the carbon steel base-plate and the stainless steel 'skin' in this case, resulting in the effective welding of the two metals together. A photomicrograph included in the article convincingly shows the bond between the two steels as joined by the explosives.

The process has been extended by the Explosives Department to the production of developmental quantities of steel plate with claddings of nickel, nickel alloys, cupro-nickel, copper, brass, titanium and several special alloys. Steel plates can be clad with metal skins from $1 / 16$-in. to 1 -in. thick, depending on the nature of the cladding material, and surface areas up to $140 \mathrm{sq}$. ft. have been successfully realized.

A most rigorous laboratory-testing programme was concurrently designed to prove the high quality of these explosive-bonded materials. This included ultrasonic inspection, bend and bond-strength tests, hardness measurements, corrosion and thermal resistance investigations. "In thermal-resistance tests, the new materials have withstood repeated cycles of $1,000^{\circ} \mathrm{F}$., followed by quenching. They also have been heated to peak temperatures of $1,750^{\circ}$ to $2,000^{\circ} \mathrm{F}$. and then quenched without failure." It is further claimed that explosively bonded plates can be cut and trimmed ". . by shearing, sawing, flame cutting, abrasive-wheel or plasma-are eutting, planing, milling or grinding. In addition, they can be formed by both hot and cold shop methods, including rolling, pressing and flanging, without bond separation."

There would appear to be little doubt as to the commercial feasibility of this new explosives metal-bonding process in view of these results; incidentally, it opens up a now vista in the use of explosives as a versatile industrial tool, one which, subject to obvious safeguards, must inevitably command the interest of all concerned with metal cladding.

\section{FOLK-LORE AND FOLK-LIFE IN BRITAIN}

\begin{abstract}
$\mathrm{T}$ HE formution in 1961 of the Society for Folk Life Studies met a long-felt wart among scholars engaged on research into the traditional ways of life in Great Britain and Ireland. Publication of a journal was planned to be one of the Society's chief functions, and the first volume, containing eight articles ranging over a diversity of subjects, sets an initial high standard of research and authorship *.

Miss Anne Buck, keeper of the Gallery of English Costume in Manchester, contributes an excellent study of the countryman's smock which does much to dispel the many fanciful theories so often held about these interesting traditional garments.

The craft of bowl-turning and spoon-making is described by Mr. F. Geraint Jenkins of the Welsh Folk Museum, and that of hand wool-combing by Mr. H. Lemon of the Wool Industries Research Association. Both these articles are well illustrated by photographs which show in detail the various processes of the crafts described.

Mr. F. Atkinson, director of the Bowes Museum, Barnard Castle, writes fully on "Knur and Spell and Allied Games"
\end{abstract}

\section{NUTRITION IN BRITAIN 1950-60}

$\mathrm{B}^{\mathrm{n}}$ ETWEEN 1940 and 1949 the National Food Survey of the Ministry of Agriculture, Fisheries and Food published two reports on Domestic Food Consumption Expenditure in the United Kingdom, and since 1950 has issued reports annually. These are based on surveys of households of different family composition and income in different parts of the country; they not only show average domestic food consumption and expenditure, but also make comparisons for regions, family size and income. The nutritional value of the food consumed is calculated and compared with a standard of requirements (the British Medical Association standard) considered necessary for satisfactory health and physical development. The reports are the only easily accessible source of information on food consumption and its trends in the United Kingdom. No other country undertakes annual national surveys of this nature.

Mr. R. Lambert has made a critical study of the reports from 1950 to $1960 *$. While admitting that they are of great value in showing national trends in consumption,

- Nutrition in Britain 1950-60: a Critical Discussion of the Standards and Findings of the National Food Survey. (Occasional Papers on Social Administration, No. 6.) By Royston Lambert. Pp. 46. (Welwyn: The Codicote
Press, 1964.) 78. 6d. in an article which helps to clear up a great deal of confused thinking about the methods of play and the locale of such games.

It is a criticism often levelled at folk-life and folk-lore scholars that their interests are mainly rural. This is confounded in an excellent article by Mr. D. McKelvie, English lecturer at Swinton Teachers' Training College, on "Aspects of Oral Tradition and Belief in an Industrial Region". Mr. McKelvie has carried out a detailed investigation of working-class life in modern Bradford, and the result is a fascinating survey of the homes, the minutix of daily life, even of the folk-lore of an urban community to-day. Mr. McKelvie is to be congratulated on his piece of research which goes far deeper than the usual economic or sociological survey so often made. His work will, we hope, be followed in other areas-in new towns, for example, or in the vast housing estates growing up as adjuncts to our more ancient cities. * Folk Life, 1. (Journal of the Society for Folk Life Studies.) Pp.
112+24 plates. (Cardiff: Folk Life Society, e/o St. Fagan's Castle,
1963).

he considers that they do not direct sufficient attention to findings which suggest that the nutrition of large families is unsatisfactory. He implies that facts are being collected for facts' sake and do not lead to action on the part of the Government. He also criticizes methods of presentation and discusses the difficulties of using dietary standards to assess nutritional levels. He believes that the survey should have broader terms of reference, that is, it should be extended by investigations of the state of nutrition of vulnerable groups, involving anthropometric, clinical and biochemical studies. By extrapolating the survey data to Britain as a whole, he estimates that a third of the population is living in households obtaining less than requirements for two major nutrients-or only just obtaining requirements-while 25 and $12 \cdot 5$ per cent are in the same position for three and four nutrients respectively. This relates, of course, only to requirements in terms of the British Medical Association standard, and does not mean that clinically evident malnutrition exists in the sections of the population concerned. He considers that certain figures for height from large families provide some indication of unsatisfactory nutrition.

Mr. Lambert's implication that the survey minimizes disquieting facts is somewhat unfair. The findings are 